\title{
Cost Analysis on ERP System Implementation amongst Malaysian SMEs
}

\author{
Mahadevan Supramaniam, Azween Abdullah, and Ramachandran Ponnan
}

\begin{abstract}
The advancement of information system led era and increased competition have forced SMEs to reengineer and integrated their business processes for better efficiency and productivity. The SMEs has begun to look into the potential of implementing enterprise software systems in adding value towards their businesses. Thus, the objective of this paper is to investigate the cost drivers of ERP implementation among the Malaysian SMEs through three main classifications: enterprise, people and implementation. Second, the study has also examined the relationship among each one of the classifiers enterprise, people and implementation. This was aimed at identifying if each one of the factors were significant in influencing the others. This study examines the objectives, via an exploratory survey of 111 companies based in Klang Valley, Malaysia. The findings has revealed that the major cost drivers for ERP implementation among the Malaysian SMEs were caused by the external ERP consultants, upgrading of skills among the employees, reengineering of business processes and the selection of ERP modules. The data and our analysis points out that people factor such as consulting experience and their involvement with the internal employees have a major impact on the ERP cost. The results have also shown that there is a significant correlation between the two cost classifiers - human resource and implementation. This study provides an avenue for further exploration on the financial aspects of ERP implementation which could have an impact on the return on investment (ROI).
\end{abstract}

Index Terms-Enterprise resource planning, small and medium sized enterprise (SMEs), business process, consultant.

\section{INTRODUCTION}

The new economy entails a more integrated and knowledge-driven enterprises that could lead to more dynamic and sustainable business growth. A closely integrated business process provides a key advantage for the SMEs to remain competitive and productive. In the current business environment, the customers often demand shorter lead-time, near perfect or even perfect delivery service, reduction of product life cycles and increasing customization. Hence, there is a pressure on SMEs to strategically improve their performance by adapting new technologies to integrated and automate their business processes.

Though the demand for ERP were first introduced to the large enterprises, the SMEs has also followed suit in the recent years [1], [2]. The challenge for SMEs implementing ERP is to learn how to deploy the technology of large enterprises without incurring high expenses [3]. Even though the ERP vendors have customized a smaller version of ERP for SMEs, the cost of implementation is still high. The

Manuscript received August 12, 2013; revised October 15, 2013.

Mahadevan Supramaniam is with the Taylor's University, Malaysia (e-mail: mahadevan.s@taylors.edu.my).
Malaysian SMEs are striving to adapt to new business landscape in order to survive and succeed. The government has been persistent in promoting the local SMEs as it offers greater economic benefits in terms of job creation, export growth, improved socio-economic, development of technology and in contributing towards economic transitions. In the context of Malaysia, available evidence suggests that local SMEs has played a pivotal role in sustaining the economic growth through continual technological development and improved product quality.

The objective of this paper is to investigate the cost drivers of ERP implementation among the Malaysian SMEs through three main classifications: enterprise, people and implementation. Second, the study has also examined the relationship among each one of the classifiers - enterprise, people and implementation.

\section{LITERATURE REVIEW}

The term "Enterprise Resource Planning" is defined as a software solution that integrates information and business processes to enable information sharing among the departments in an organization. The range of functionality and use of ERP systems has further expanded in recent years to include business intelligence, customer relationship management (CRM) and electronic commerce. Common examples of ERP systems available include SAP ERP, Oracle, Baan and PeopleSoft. ERP system is being used by large organizations to support and integrate various processes. According to a survey conducted by Somer \& Nelson, most of the US companies are allocating $43 \%$ of their annual budget towards upgrading their enterprise systems. This indicates that the companies could have reaped the potential benefits from the implementation of ERP in terms of revenue growth and business expansion.

The enormous results gained by the large corporation have attracted the SMEs to explore the use of ERP. The SMEs were further motivated through the introduction of ERP for small enterprises, which are more cost effective. There were many studies associated with adoption of ERP among SMEs [4], [5]. According to Oliver and Romm (2000), the main influencing factors for adopting ERP were to improve operational efficiency, data integration and to avoid competitive disadvantage.

The SMEs are capable of enhancing their operational and business strategy by implementing an ERP system [6]. At the moment, most of the ERP vendors like SAP, Oracle and Microsoft are aggressively penetrating the SME segment to the extent of developing customized solutions to cater the SMEs. Many Malaysian SMEs are in some stage of implementing ERP systems to remain competitive and 
productive.

Currently the challenges being faced by the Malaysian SMEs are the escalating cost of an ERP implementation due to many factors. The adoption and implementation of ERP systems is a crucial issue if referred to small and medium sized enterprises. The main problem is that the cost of implementation of ERP, intended as the process of customization of the ERP system towards the actual enterprise business processes, overtakes the cost of ERP acquisition. Thus, there is a need to use the same workflow systems for both modelling the enterprise business processes and designing the ERP. The ERP implementation itself may also prove to be more challenging for a SME. A SME is less likely to have a robust IT team in house. Thus, during an ERP implementation more consultants are desired versus an implementation at a large firm. This will increase the ERP implementation percentage costs for a SME above that of a large firm. However, SMEs also have a limitation in that they can't afford to hire a team from large consultancies and therefore, are often limited to their own scarce resources and the help provided by the vendor.

There are multiple studies being done focusing on the cost of ERP implementation around the world (e.g., [7], [8]). Apart from that a plethora of empirical studies have used the costing framework, which emphasized on enterprise, human resource and implementation cost groupings as a theoretical foundation for investigating the investment of new technologies.

As an example the researcher, Francalanci (2001) has concluded that the cost of implementation is dependent on a usable measure of size. According to the author, there are three major components for such a size metric, which are size of the organization, size of the configuration and size of the implementation. Kusters et al. (2007) were focusing on both size and other additional cost drivers such as system implementation cost, business reorganization cost, human resource cost and organizational change cost. There seems to be similarities in the literature on the multi-dimensional related cost drivers.

One of the main questions asked by management in charge of an Enterprise Resource Planning (ERP) project is "How much does it cost"? It is very difficult to provide a direct answer to this question and academic literature prefers to investigate cost drivers [9]; while remaining otherwise scarce on the matter of the level of cost. The aim of this research is to examine factors of implementation cost and specifically the research question "which factors substantially influence ERP implementation cost?"

The issue of factors that impact ERP implementation cost is discussed explicitly by Stensrud (2001). In his research, he wondered if the existing body of knowledge developed for software cost estimation was applicable to estimation of ERP implementation effort.

Several software cost estimation approaches exist, such as the constructive cost model developed by Boehm [10]. The approach states that under normal circumstances development costs are a function of project size. Since the circumstances in which a project takes place are rarely 'normal', the estimate must be refined using additional cost drivers. As an example, one of the models proposed by Boehm is as follows:
Stensrud (2001) concluded that since most software cost estimation (SCE) approaches are based upon the use of the number of lines of source code [10] or some synthetic variable such as function points to assess the size of the project, these approaches are not immediately applicable. An ERP implementation project may contain some software development, but will also contain substantial modelling, installation and reorganization efforts. It seems unlikely that a one-dimensional measure of software size will capture this complexity. He did however conclude, that a measure of size for an ERP implementation project would likely be multi-dimensional; using a combination of measures such as the number of users, the number of reports that have to be designed, and the number of ERP modules. Drawing upon the empirical evidence of other scholars, the current study uses three main classifications to identify the implementation cost, which are enterprise, people and implementation cost.

\section{METHODOLOGY}

\section{A. The Sample Size}

The objective of this study is to identify the major cost drivers of ERP implementation amongst Malaysian SMEs. Therefore the samples of interest in the population will be restricted to that organization that uses ERP based system. A total of 210 sample firms' detail was collected. The lists of sample firms were obtained from several sources including Small and Medium Industries Development Corporation (SMIDEC), Federation of Malaysian Manufacturers (FMM) and Multimedia Development Corporation Malaysia (MDeC). A total of 111 companies responded to the questionnaire (a response rate of 27.6 percent). This response rate is slightly over the usual response rate in Malaysian based surveys (ranging from 15-25 percent). However it is justifiable to explore the data even if it is lower than 15 percent, if it is an explanatory based study.

\section{B. The Survey Instrument}

The survey questionnaires related to costing strategies were adopted from Kusters et al. (2007). The main questionnaires were divided into two sections - Section A, Section B and Section C. Section A seeks general information (demographic profile) of the sample SMEs, such as the core business area, year of establishment, ownership structure and annual sales turnover. Section B was designed to examine the preferred variables for ERP adoption by categorizing it through TOE framework. Section C was designed to analyze the cost structure of the ERP implementation based on the enterprise related cost, people's cost and implementation cost.

\section{Data Analysis}

Analysis of the completed questionnaire was conducted through SPSSWIN software. First, a frequency distribution analysis was conducted to determine the demographic profile of the sample SMEs. Second, reliability and factor analysis was conducted to determine the reliability of the instruments used and the determination of the pertinent challenging factors to the SMEs based on the cost classifications. Factor analysis was done on the variables which have a mean value of 3.00 and above. The factor analysis was done using axis 
factoring approach with varimax rotation. Items in several scales returned factor loadings lower than 0.70 threshold value.

Partial least square (PLS) were used to assess the adequacy of measurement models for the latent constructs as it suits well for exploratory research such as the present study. Second, PLS conducts simultaneous analysis for both the measurement model and the structural or theoretical model. Third, PLS estimation is well suited for a small sample sized research such as the current study. In line with PLS protocols, the robustness of the reflective measurement scales were evaluated in the following context:

1) Assessment of the convergence of the scales where items with factor loadings higher than 0.60 is accepted

2) Measurement of the reflective scales internal consistency which is determined by the composite reliability value higher than 0.60

3) Examining the average variance extracted (AVE) which should be higher than 0.50

4) Examining the discriminant validity of the model

Following the measurement model assessment, the structural model in the study is examined using two criterions: i) the $R^{2}$ of the model and ii) the estimates of the path coefficients need to be statistically significant and done using the bootstrapping procedure.

\section{DATA ANALYSIS AND FINDINGS}

The descriptive statistics suggests that a wide variety of industries were represented and the information was provided by top level IS executives. Table I shows a higher representation from the manufacturing industries compared to other industries.

TABLE I: COMPANIES BY INDUSTRY

\begin{tabular}{|l|c|}
\hline \multicolumn{1}{|c|}{ Industry Type } & SMEs \\
\hline Retail & 27 \\
\hline Banking and Investment Institutions & 22 \\
\hline Manufacturing & 39 \\
\hline Professional services & 11 \\
\hline Utilities & 12 \\
\hline TOTAL & 111 \\
\hline
\end{tabular}

The annual sales turnover of major ERP users under the SMEs' category was in between five to ten million ringgit as shown in Table II. The ERP system for SMEs comes in different package and cost. The cost of MNC package was very expensive compared to the SME's package.

TABLE II: ANNUAL SALES TURNOVER

\begin{tabular}{|l|c|}
\hline Annual Sales Turnover & SMEs \\
\hline Less than RM200,000 & 10 \\
\hline Between RM200,000 - RM1 million & 19 \\
\hline Between RM1 - RM5 million & 22 \\
\hline Between RM5 - RM10 million & 35 \\
\hline More than RM10 million & 25 \\
\hline
\end{tabular}

Table III and IV provides the means and standard deviations of the scores related to each of the variables used in the factor analysis for the SMEs. Table III shows the mean score for five variables ranged between 3.10 - 3.66 points. Note that it is normal to gauge variables with mean score of
3.00 and above in statistical context. The variables with mean score of lower than 3.00 would be excluded from the discussion.

In the context of enterprise, business process scored the highest mean while in terms of human resource, the external consultant and upgrading of skills and experience were considered the major contributing factors towards the cost of ERP implementation. In terms of implementation, the SMEs have recognized that the number of ERP modules and project management as the key contributor towards the cost factor with a mean of more than 3.00 .

TABLE III: MEAN SCORE AND STANDARD DEVIATIONS OF THE FACTORS

\begin{tabular}{|c|c|c|c|}
\hline \multirow[b]{2}{*}{ No } & \multirow[b]{2}{*}{ Variables } & \multicolumn{2}{|c|}{ SMEs } \\
\hline & & Mean & Std Dev. \\
\hline \multicolumn{4}{|c|}{ Enterprise } \\
\hline E1 & Size of business & 2.88 & 0.875 \\
\hline E2 & Annual Turnover & 2.79 & 0.861 \\
\hline E3 & Business Process & 3.33 & 1.883 \\
\hline E4 & Management Structure & 2.15 & 0.778 \\
\hline \multicolumn{4}{|c|}{ Human Resource } \\
\hline $\mathrm{H} 5$ & Internal Employee & 2.54 & 0.639 \\
\hline H6 & ERP Consultant (External) & 3.66 & 0.827 \\
\hline $\mathrm{H} 7$ & Skills and Experience & 3.57 & 0.931 \\
\hline $\mathrm{H} 8$ & Qualifications & 2.99 & 0.745 \\
\hline \multicolumn{4}{|c|}{ Implementation } \\
\hline I9 & Types of ERP Modules & 3.28 & 0.736 \\
\hline $\mathrm{I} 10$ & User license & 2.59 & 0.833 \\
\hline I11 & Project Management & 3.10 & 0.885 \\
\hline $\mathrm{I} 12$ & External IS support & 2.83 & 0.903 \\
\hline
\end{tabular}

Table IV represents the variables used for factor loading based on the mean value of 3.00 and above. The factor loading was in the range of 0.60 to 0.90 thus exceeding the recommended minimum of 0.60 . The composite reliability was also higher than 0.60 , denoting strong internal consistency. We also see that the average variance extracted by all of the first order factors in both phases was between $56 \%$ to $100 \%$ (refer to Table IV).

TABLE IV: CONVERGENCE, INTERNAL CONSISTENCY ASSESSMENT AND

\begin{tabular}{|c|c|c|c|c|}
\hline & FOR S & & & \\
\hline Final Variables & E1 & E2 & E3 & E4 \\
\hline Factor Loading & - & 0.878 & - & - \\
\hline Composite Reliability & \multicolumn{4}{|c|}{0.870} \\
\hline AVE & \multicolumn{4}{|c|}{0.803} \\
\hline Final Variables & $\mathrm{H} 5$ & H6 & $\mathrm{H} 7$ & $\mathrm{H} 8$ \\
\hline Factor Loading & - & 0.920 & 0.882 & - \\
\hline Composite Reliability & \multicolumn{4}{|c|}{0.811} \\
\hline AVE & \multicolumn{4}{|c|}{0.840} \\
\hline Final Variables & I9 & $\mathrm{I} 10$ & I11 & $\mathrm{I} 12$ \\
\hline Factor Loading & 0.930 & 0.862 & 0.812 & - \\
\hline Composite Reliability & \multicolumn{4}{|c|}{0.810} \\
\hline AVE & \multicolumn{4}{|c|}{0.703} \\
\hline
\end{tabular}

Table $\mathrm{V}$ provides information on the correlations between all the first order constructs. Based on this data, we did not see that the bivariate correlations exceeding the respective square root of AVE measures. 
TABLE V: DISCRIMINANT ANALYSIS FOR SMES

\begin{tabular}{|c|c|c|c|}
\hline $\begin{array}{c}\text { Challenging } \\
\text { Factors }\end{array}$ & Enterprise & HR & Implementation \\
\hline Enterprise & 0.82 & & \\
\hline HR & 0.32 & 0.81 & \\
\hline Implementation & -0.13 & 0.72 & 0.84 \\
\hline
\end{tabular}

These results support the validity and reliability of the measurement model and provide a sound basis for examining the structural relationship required to analyze the relationship in between the cost factors. The path coefficients and $p$ values were reported in Table VI. We can see that the R2 values for the endogenous constructs ranged at 0.32 , indicating a weak to moderate structural model [11]. Based upon 111 samples run, the path relationship emerging from enterprise and human resource factors to implementation factor is statistically significant at $99.9 \%$ confidence level (i.e. $p>$ 0.001). Enterprise factor seems to have an insignificant path association with human resource factor.

TABLE VI: STRUCTURAL MODEL RESUlTS FOR MNCS AND SMES

\begin{tabular}{|c|l|}
\hline Relationship & \multicolumn{1}{|c|}{ Significance } \\
\hline $\mathrm{E} \rightarrow \mathrm{I}$ & $\beta=0.25 ; t=5.55^{* *}$ \\
\hline $\mathrm{H} \rightarrow \mathrm{I}$ & $\beta=0.23 ; t=4.57^{* *}$ \\
\hline $\mathrm{E} \rightarrow \mathrm{H}$ & $\beta=-0.33 ; t=6.15^{* *}$ \\
\hline $\mathrm{T}=\mathrm{R}^{2}$ & 0.32 \\
\hline
\end{tabular}

\section{DisCUSSION OF RESULTS}

The research findings were presented and discussed in two aspects. The first aspect discussed the importance of variables based on the classifications through factor loading. Among the independent variables, business process, external consultants, upgrading of skills/experience, types of ERP modules and project management were seem to be the significant drivers of ERP costs. It could be noted from the previous studies that most companies do invest their time and money towards the reengineering of their business process before the implementation of ERP. Hence, the SMEs has regarded the business process as the contributing factor towards the cost of ERP.

In the human resource classification, the SMEs were incurring the highest cost from the external consultant. This is consistent with results from previous research, which have mentioned the lack of ERP consultants in the SMEs and the high cost of hiring external consultants for a period of time to implement and maintain the ERP system. Apart from that the SMEs are incurring a major cost from the upgrading of skills for the employees. This could be due to the retraining process of the current employees in becoming ERP users. Apart from that, the SMEs are also working towards upgrading the skill level of their employees to ensure a smooth ERP management. In terms of implementation, the SMEs has regarded that the cost increases with the selection of ERP modules that need to be installed such as sales, procurement, financial and inventory. The user license was also seen as a major cost contributor towards the ERP cost.

The overall results seems to contradict the current studies which have indicated that their major cost overruns are from the implementations while the Malaysian SMEs has regarded that the human resource as the major cost contributors towards the implementation of ERP system. This could be due to the fact that it is difficult to maintain an ERP system after the first roll out due to the lack of internal technical experts. In a long run, the SMEs were forced to appoint an external consulting firm to manage the complex system on a daily basis, which is more expensive. Hence the IT outsourcing business is fast becoming a lucrative business segment in the Malaysian industry. These results could imply that the real obstacle to ERP diffusion among the local SMEs could be the lack of internal ERP expertise and not the cost of the product alone.

The second aspect of this study correlates the three main classifications within the SMEs. The SMEs have a significant relationship in between enterprise to implementation and human resource to implementation as in Table VI. It shows an insignificant relationship in between enterprise and human resource. The SMEs are very particular in ensuring that the cost of implementation is driven based on the scale of business process of the company and its integration towards the legacy systems. Apart from that the organizations are also very keen on planning and developing their human capital as it is directly associated with the implementation cost.

It is also surprising to note there is a lack of cost dependence in between the enterprise and the human resource. This could be because since the top management has already given the nod for the ERP implementation, there is a very little role and cost dependency during the implementation as it is more technical and closely related to the human resource and implementation cost.

\section{CONCLUSION}

The purpose of this study is to identify the main variables for ERP implementation cost and identify the correlations in between the three main constructs of the ERP costing. Though the empirical data clearly shows that SMEs have different approaches in adopting ERP system, there are no large differences among them. The differences could only be attributed towards the higher cost concentration on the human resource instead of the implementation. This pattern is partially different from what have been observed earlier through the literature reviews.

A usual belief is that the cost of the user licenses is a central factor of cost. Nevertheless, our analysis has not revealed evidence of such a relationship. The importance of the factor consulting cost clearly stands out in the data and our analysis reveals a new major cost driver.

As empirical research attempts to measure business perceptions, some limitations or biases are unavoidable. Consequently, as is always the case in empirical research, results should be interpreted with some caution. The extrapolation of these results to large companies is not appropriate, and future research should, therefore, be conducted for them. Further research should be focused towards finding a permanent solution towards reducing the cost of implementation and the maintenance of the ERP system in a long run as this has a direct impact towards the performance of the organizations. 


\section{REFERENCES}

[1] D. A. Cook and T. R. Leishman, "Lessons learned from software engineering consulting," The Journal of Defense Software Engineering, vol. 17, no. 2, pp. 4-6, 2004.

[2] E. Knorr, "ERP's rough waters," Upside, vol. 11, no. 12, pp. 209-213 December, 1999.

[3] C. Francalanci, "Predicting the implementation effort on ERP projects," Journal of Information Technology, vol. 16, no. 1, pp. 33-48, 2001.

[4] L. Elbertsen and R. V. Reekum, "To ERP or not to ERP? Factors influencing the adoption decision," International Journal of Management and Enterprise Development, vol. 5, pp. 310-330, 2008.

[5] T. H. Lee, Y. B. Moon, and H. Lee, "Enterprise resource planning survey of Korean manufacturing firms," International Journal of Management and Enterprise Development, vol. 3, no. 6, pp. 521-533, 2006.

[6] W. -H. Tsai, T. W. Lin, S. -P. Chen, and S. -J. Hung, "Users' service quality satisfaction and performance improvement of ERP consultant selection," International Journal of Business and System Research, vol. 1, no. 3, pp. 280-301, 2007.

[7] M. Al-Mashari, M. Zairi, and K. Okazawa, "Enterprise Resource Planning (ERP) implementation: A usefulroad map," International Journal of Management and Enterprise Development, vol. 3, no. 1/2, pp. 169-180, 2006.

[8] D. A. Cook and T. R. Leishman, "Lessons learned from software engineering consulting," The Journal of Defense Software Engineering, vol. 17 , no. 2 , pp. 4-6, 2004.

[9] R. J. Kusters, F. J. Heemstra, and A. Jonker, "Determining the costs of ERP implementation," in Proc. the 9th International Conference on Enterprise Information Systems, vol. Database and Information Systems Integration, pp. 102-110, 2007.

[10] B. Boehm and B. M. Steece, "Disaggregating and Calibrating the CASE Tool Variable in COCOMO II," IEEE Transactions on Software Engineering, pp. 1009-1022, 2002.

[11] W. W. Chin, B. Marcolin, and P. Newsted, "A partial least squares latent variable modeling approach for measuring interaction effects: Results from a Monte Carlo simulation study and an electronic-mail emotion/adoption study," Inform. Systems Res, vol. 14, no. 2, pp. 189-217, 2003.

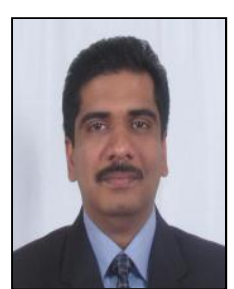

Mahadevan Supramaniam is the head of R\&D Commercialization and SAP ERP Certified Consultant and currently attached to Taylor's University, Malaysia. Prior to joining Taylor's University, he was an R\&D engineer (Software) in Motorola Malaysia and Xyratex, United Kingdom. His expertise and research interest lies in the area of Enterprise Resource Planning (ERP) and electronic banking.

Azween Abdullah has been contributing to research, teaching, consulting and in administrative services to the institutions that he has been working for thus far. His work experience includes twenty four years as a lecturer in institutions of higher learning and as director of research and academic affairs at two institutions of higher learning, vice-president for educational consultancy services, ten years in commercial companies as Software Engineer, Systems Analyst and as a computer software developer and IT/MIS consultancy and training. He is currently a senior academic at Taylors University $\mathrm{He}$ is a fellow of the British Computer Society and members of IEEE and ACM. His area of specialization in ICT is in Medical Computing and Computer Security.

Dr. Ramachandran Ponnan is currently a Senior Lecturer at the School of Communication, Taylor's University, Malaysia. Prior to joining Taylor's University, he was the R\&D director for the National Broadcasting company in Malaysia. His expertise and research contribution lies in the area of broadcasting, digital media and broadcasting process integration. He has written numerous journals and articles for the past twenty years. 